\title{
An estimation of the dynamical isolation of the tropical lower stratosphere using UARS wind and trace gas observations of the quasi- biennial oscillation
}

\author{
M. R. Schoeberl ${ }^{1}$, A. E. Roche ${ }^{2}$, J. M. Russell $\mathrm{III}^{3}$, D. Ortland ${ }^{4}$, P. B. Hays ${ }^{4}$ and J. W. Waters 5
}

\begin{abstract}
Upper Atmosphere Research Satellite tropical wind and constituent measurements are used to estimate an upper limit of mid-latitude to tropical trace gas exchange by examining the phase of the $\mathrm{N}_{2} \mathrm{O} / \mathrm{CH}_{4}$ ratio with respect to the Quasi-Biennial Oscillation winds. Assuming a simple diffusive model for tropical - mid-latitude exchange in the $20-28 \mathrm{~km}$ region, the mixing times are estimated to be at least 18 months, and, we estimate an eddy mixing coefficient of $7 \times 10^{8} \mathrm{~cm}^{2} / \mathrm{sec}$. This low mixing rate suggests that if significant chemical mixing into the lower tropical stratosphere occurs, as has been suggested by observational data, then this mixing must take place below $20 \mathrm{~km}$.
\end{abstract}

\section{Introduction}

An important issue for assessing the impact of a future fleet of stratospheric aircraft is the rate of mixing of mid-latitude stratospheric air into the tropical regions. If mid-latitude aircraft $\mathrm{NO}_{\mathrm{y}}$ pollution can be mixed into the lower tropical stratosphere, the polluted air could be lofted to higher altitudes by the stratospheric extension of the tropical Hadley circulation [Plumb, 1996]. At higher altitudes, the $\mathrm{NO}_{\mathrm{y}}$ pollution will increase ozone loss and increase the net impact of aircraft emissions on the stratosphere [NASA, 1995].

Transport of trace gases out of the tropical regions to midlatitudes occurs through eddy mixing and through the stratospheric Brewer-Dobson circulation. Recent trace gas measurement data suggest that there is fairly rapid communication between the lower tropical stratosphere and mid-latitudes [Prather and Avallone, 1996, Minshwaner et al., 1996, Volk, et al., 1996]. From the altitude change of several trace gases, these authors argued that midlatitude air is entrained within the tropical regions between $16-21 \mathrm{~km}$ region within about 13.5 months. They computed that at $21 \mathrm{~km}$, about $45 \%$ of the air was of mid-latitude origin.

At higher altitudes, between 21 and $40 \mathrm{~km}$, the trace gas gradient between mid-latitudes and the tropics is larger suggesting a stronger barrier to tropical - mid-latitude exchange. The strength of the trace gas gradient varies with season, and also appears to be partially under the control of the QBO circulation [Trepte and Hitchman, 1993; Grant et al., 1996]. Transport out of the tropical middle and upper stratosphere is characterized by "events" rather than a steady mean circulation. In these events mid-latitude eddies draw material out of the tropics. In the Waugh [1996] simulations

\footnotetext{
${ }^{1}$ NASA Goddard Space Flight Center

${ }^{2}$ Lockheed Palo Alto Research Laboratories

3 NASA Langley Research Center

${ }^{4}$ University of Michigan

5 Jet Propulsion Laboratory
}

Copyright 1997 by the American Geophysical Union.

Paper number 96GL03370

0094-8534/97/96GL-03370\$05.00 filaments of mid latitude material intrude deeply into the tropical region. These simulations suggests isotropic eddy mixing with the transport of tropical gases into mid-latitudes accompanied by eddy transport of mid-latitude trace gases into the tropics.

Accompanying the mixing of midlatitude air into and out of the tropics, there is the large scale ascent of air at a rate of 0.2 to $0.4 \mathrm{~mm} / \mathrm{sec}$ [Rosenfield et al., 1989; Rosenlof 1995], and the upward propagation of isopleths of total hydrogen $\left(2 \mathrm{CH}_{4}+\right.$ $\mathrm{H}_{2} \mathrm{O}$ ) [Mote et al., 1996]. The lower tropical stratosphere upwelling is further modulated by the secondary circulation associated with the quasi-bjennial oscillation (QBO). The magnitude of the QBO secondary circulation can be derived from thermal wind arguments [Plumb and Bell, 1982] and is about 0.1 $\mathrm{mm} / \mathrm{sec}$. The circulation associated with the QBO also modulates the trace gas and aerosol gradients at the tropical/mid-latitude boundary, concentrating the aerosol distribution in the tropical region during the easterly shear phase and spreading the distribution in the westerly shear phase [Trepte and Hitchman, 1993].

The regular modulation of the tropical upwelling vertical velocity by the QBO produces a corresponding modulation of the trace gases distributions within the tropics [Hasebe, 1994]. As will be shown below, the phase relation between the trace gases and the QBO wind can be a sensitive measure of exchange between mid-latitudes and the tropics, and thus can be used to estimate the rate of this mixing between these two regions.

\section{The QBO circulation and tracer transport}

Irrespective of the generating mechanism for the QBO, the zonal mean secondary circulation can be diagnosed using the thermal wind and thermodynamic equations. These zonal mean fields are perturbations from the time mean fields denoted by $>$. At the equator, the zonal mean perturbation wind, $U$, associated with the QBO can be related to the zonal mean temperature perturbation, $T$, through the thermal wind equation,

$$
\partial U / \partial z=-k \partial^{2} T / \partial y^{2}
$$

where $k=a R / 2 H \Omega$ where $\mathrm{R}$ is the dry air gas constant, $H$ is the atmospheric scale height $(\sim 7 \mathrm{~km})$, a is the earth's radius, $\Omega$ is the earth's angular rotation rate, $z$ is log-pressure height $(z=$ $H \log \left(p_{o} / p\right)$ ) where $p$ is pressure and $p_{o}$ is the surface pressure, $y$ is the distance from the equator. If we assume, as is usually done, that all of the QBO perturbation fields have a Gaussian, equator centered, meridional structure with a scale $L$, e.g. $T(y, z)$ $=T(z) \exp \left(-y^{2} / L^{2}\right)$, then at the equator,

$$
\partial U / \partial z=2 k T L^{-2}
$$

The thermodynamic equation may now be used to estimate the vertical velocity of the QBO secondary circulation. The zonal mean QBO perturbation fields are smaller than the zonal mean, time mean fields. Neglecting the vertical transport of heat [Hasebe, 1994], the residual vertical velocity (w) from the perturbation thermodynamic equation is, 


$$
w=-\left(\frac{\partial \theta}{\partial t}+\alpha, \theta\right) / \frac{\partial<\theta>}{\partial z}
$$

where $\alpha_{r}$ is the radiative damping rate (Newtonian cooling), $\theta$ is the potential temperature, $\theta=T \exp (\kappa z / H)$, where $\kappa=2 / 7$. Changes in the heating rate due to ozone advection (included by Hașebe, 1994] are neglected. We now introduce the perturbation trace gas mass continuity equation,

$$
\frac{\partial \chi}{\partial t}+w \frac{\partial<\chi>}{\partial z}=-\alpha_{m} \chi-\alpha_{c} \chi
$$

where $\chi$ is the zonal mean, trace gas mixing ratio perturbation from the time mean, $\alpha_{m}=2 K / L^{2}$ where $K$ is the meridional eddy diffusion coefficient) and $\alpha_{\mathfrak{c}}$ is the chemical relaxation rate. If a ratio of trace gases, $\chi=\chi_{A} / \chi_{B}$, is used in (4) then the perturbation field is formed after the ratio is taken, and the chemical source term becomes

$$
{ }^{-\alpha}{ }_{C A} \chi_{A}^{\prime} /<\chi_{A}>+\alpha_{C B} \chi_{B}^{\prime} /<\chi_{B}>\text {. }
$$

Vertical eddy mixing and meridional advection are assumed negligible [e.g. Holton, 1986]. The use of Fickian type diffusion to describe the effects of meridional eddy mixing to mid-latitudes cannot be formerly justified, but for the mixing rate arguments we use below, Fickian diffusion is an adequate representation. Note that meridional mixing has been previously neglected in the QBO trace gas analysis of Hasebe [1994].

Now consider a zonal mean perturbation with the QBO frequency, $\sigma$, and vertical wavelength, $\gamma$. For the QBO, which has a period of about 27 months, $\alpha_{r} \theta$ is much greater than the thermal inertia term. Using equations (2-4) to relate the perturbation trace gas mixing ratio to the zonal wind,

$$
\chi\left(\sigma-i\left(\alpha_{m}+\alpha_{c}\right)\right)=\frac{\gamma U \alpha_{r} L^{2}\left(\frac{\partial<\chi>}{\partial z}\right)}{2 k\left(\frac{\partial T}{\partial z}+\kappa T / H\right)}
$$

where all the variables except time means are now assumed to be proportional to $\exp (i(\gamma+\sigma t))$.

Eq. (5) shows that the phase lag

$$
\phi=\tan ^{-1}\left(\left(\alpha_{m}+\alpha_{c}\right) / \sigma\right)
$$

between the trace gas perturbation and the QBO wind field is controlled by the chemical relaxation time constant and the meridional mixing rate constant. If the chemical relaxation time and meridional mixing rate are much smaller than the QBO frequency then the trace gas perturbation will be approximately in phase with the perturbation zonal wind. By estimating the phase between the QBO in long lived tracers and the zonal wind, we can thus estimate the mixing rate from extratropics within the $\mathrm{QBO}$ region.

Figure 1 shows a time series of the ratio of $\mathrm{N}_{2} \mathrm{O}$ to $\mathrm{CH}_{4}$ (V7) measured by the Cryogenic Limb Array Spectrometer (CLAES) aboard UARS, zonally and latitudinal averaged between $8^{\circ} \mathrm{S}$ and $8^{\circ} \mathrm{N}$ from 1992 through spring 1993 . The ratio shown is the deviation of the ratio from the time mean. The validation of the CLAES $\mathrm{CH}_{4}$ and $\mathrm{N}_{2} \mathrm{O}$ data is discussed by Roche et al. [1996]; the data should be good down to about $22 \mathrm{~km}$ in the tropics with a random error of about $7 \%$. Using the tracer ratio provides greater sensitivity over a deeper altitude range than either tracer alone. It turns out that the CLAES methane field is so flat across the tropics that most of the signal and Gaussian-like meridional variation is dominated by the $\mathrm{N}_{2} \mathrm{O}$ field.

Figure 1 clearly shows the close correlation between the Singapore zonal wind and the change in the ratio $\mathrm{N}_{2} \mathrm{O} / \mathrm{CH}_{4}$ near the zero wind line. The lifetime of $\mathrm{CH}_{4}$ and $\mathrm{N}_{2} \mathrm{O}$ at these altitudes is long enough that chemical loss can be generally neglected in (5) compared to the QBO frequency although recent studies suggest a shorter lifetime (about a year) for $\mathrm{N}_{2} \mathrm{O}$ [Minschwaner et al., 1993] near $30 \mathrm{~km}$. One and two month phase shift lines are also shown on the figure. Although the short data record precludes the exact estimate of the phase between the QBO and the change in the $\mathrm{N}_{2} \mathrm{O} / \mathrm{CH}_{4}$ ratio, the phase lag/lead appears to be less than 1 month through most of the period. At the upper levels (above about $28 \mathrm{~km}$ ) the phase shift is more difficult to estimate and appears larger.

From the phase relation (6) we compute that a one month phase shift implies a mixing time $\left(1 / \alpha_{m l}\right)$ of about 18 months assuming a 27 months QBO period. We emphasize that this is the upper limit for the mixing time since the phase shift could be smaller than a month. A longer data record is required for greater precision.

Since we are considering the effect of mixing on the $Q B O$, the tracer mixing scale is also the QBO meridional scale, $L$. The QBO scale can be determined by matching the QBO thermal perturbations observed by the Microwave Limb Sounder with the wind shear values determined by the High Resolution Doppler Imager (HRDI) [Ortland et al., 1996] in Eq. (2). We have found that a mixing scale of $1800 \mathrm{~km}$ provides a reasonable fit. Using $L=1800 \mathrm{~km}$ gives $7 \times 10^{8} \mathrm{~cm}^{2} / \mathrm{sec}$ which is significantly smaller than $2-4 \times 10^{9} \mathrm{~cm} 2 / \mathrm{sec}$ used by most $2 \mathrm{D}$ models for tropical mixing [NASA, 1993] implying more tropical isolation of the mid-stratosphere than is used by current 2D models. Weisenstein et al. [1996] recently adopted the lower tropical diffusion coefficient of $3 \times 10^{8} \mathrm{~cm}^{2} / \mathrm{sec}$ for the AER model which they found better isolated aircraft effluent in the northern mid-latitudes.

\section{Other evidence for tropical isolation}

Supporting observations for tropical isolation comes from the tropical water vapor data observed by the Halogen Occultation Experiment (HALOE). The quality of the HALOE (V17) data is discussed by Harries et al. [1996]. Figure 2 shows a time series of tropical water vapor with the time mean removed following Mote et al. [1996]. Clearly evident in the data set is the ascending water vapor anomalies associated with the diabatic circulation. The ascent of these anomalies is modulated by the weaker QBO secondary circulation. The water vapor anomalies have their origin in the seasonal variation of tropical tropopause temperatures which produces relatively dry and moist regions as discussed by Mote et al. The fact that these features remain fairly coherent throughout the lower tropical stratosphere at roughly the same amplitude suggests low mixing into the tropical stratosphere and low vertical diffusion.

The vertical transit time for the water vapor features to $35 \mathrm{~km}$ is about $1.5-2$ years. Overlaid on the figure are HRDI winds. The HRDI winds are in good agreement with the Singapore winds. From Figure 2, the water vapor anomalies appear to be coherent up through the QBO region $(30 \mathrm{~km}$ ) up to $35 \mathrm{~km}$ where the semiannual wind oscillation begins to dominate. As an example, a tongue of high water vapor begins ascending at date 93.5 and reaches $32.5 \mathrm{~km}$ by time 95.5 . The initial perturbation value is $0.5 \mathrm{ppm}$ and is reduced to $0.15 \mathrm{ppm}$ in transit. The computed decay time for this water vapor perturbation is $\mathbf{2 0}$ months, and assuming that this decay is due to the meridional mixing with a scale of $1800 \mathrm{~km}$, this gives a mixing rate $6.25 \times 10^{8} \mathrm{~cm} / \mathrm{sec}^{2}$ over the $10 \mathrm{~km}$ altitude range consistent with our QBO estimate.

Finally, QBO numerical models require some level of isolation or turbulent transport of momentum will significantly reduce the amplitude of the oscillation and increase the period. Dunkerton [1991] tested several values of $K_{y y}$ in his QBQ model and found that $K_{y y}$ values much greater than about $5 \times 10^{7}$ $\mathrm{cm}^{2} / \mathrm{sec}$ created problems. Dunkerton's value is significantly 

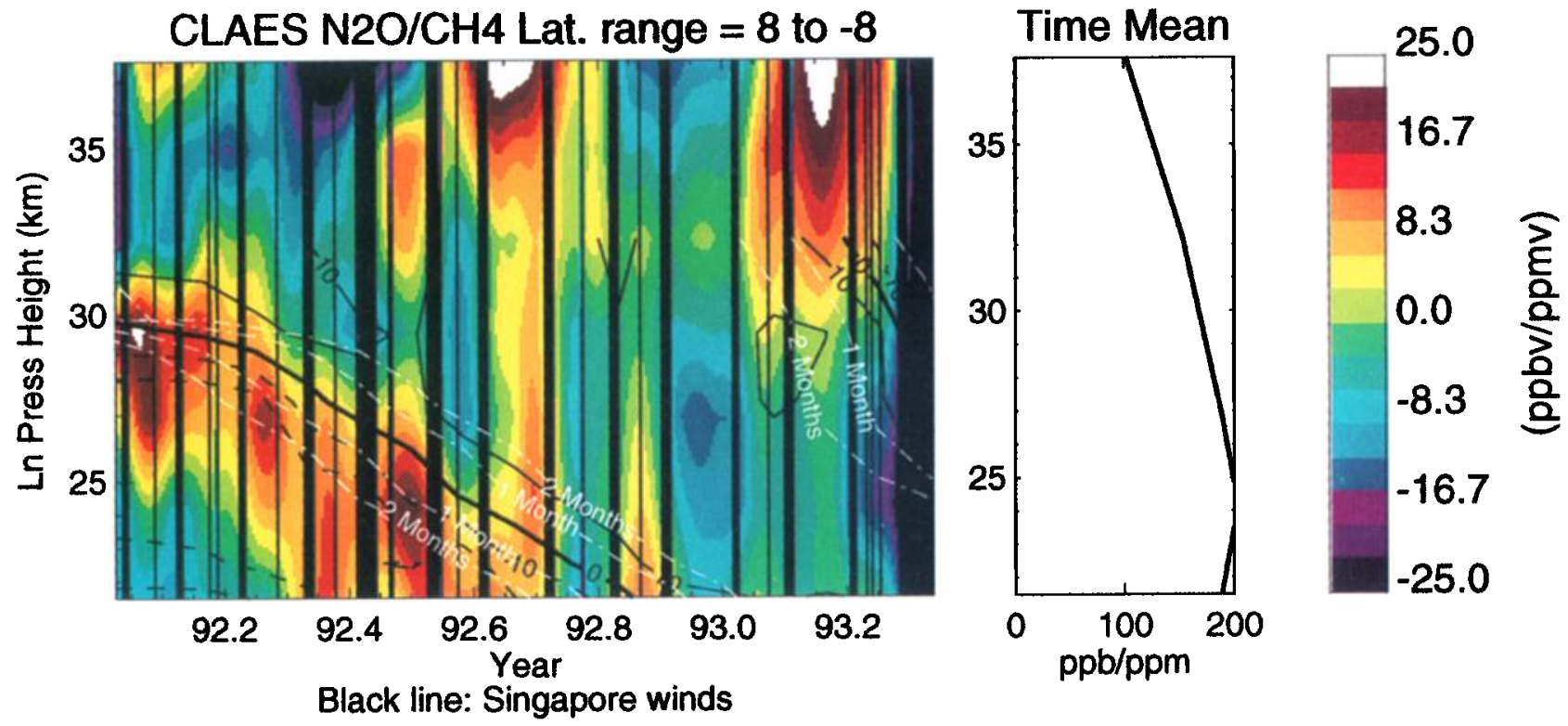

Figure 1 CLAES (v7) observations of $\mathrm{N}_{2} \mathrm{O} / \mathrm{CH}_{4}$ averaged between $8^{\circ} \mathrm{N}$ and $8^{\circ} \mathrm{S}$. Left panel shows time series verses altitude with time average removed. Time averaged values are shown on the right panel. Units are ppbv/ppmv. Overlaid black lines are the Singapore zonal winds. The heavy black line is the zero wind line. Dashed white lines show the one month and two month phase leads and lags from the zero wind line.
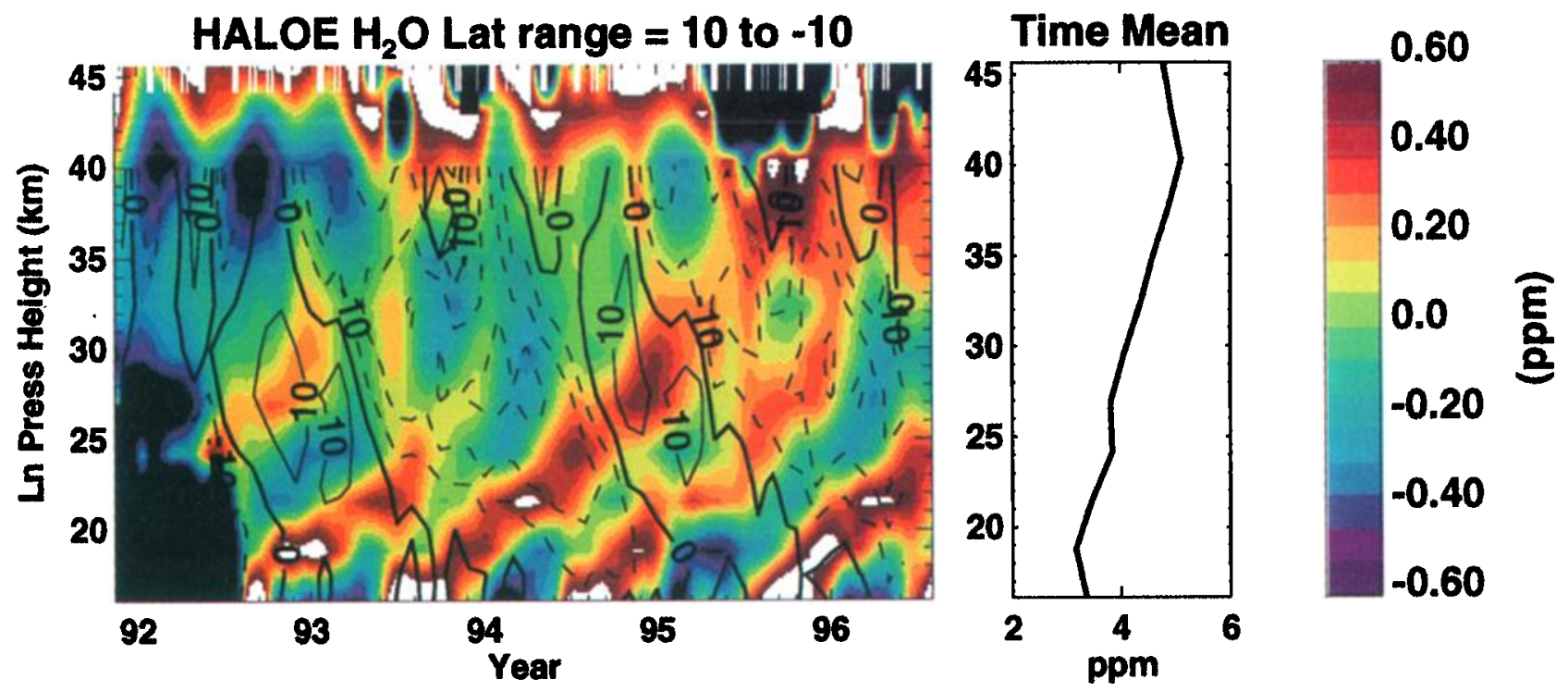

Figure 2 HALOE (v18) water vapor time series verses altitude, averaged between $10^{\circ} \mathrm{N}$ and $10^{\circ} \mathrm{S}$. Time average water vapor is shown on the right panel. Black contours show the HRDI observed zonal mean equatorial zonal winds. Tick marks on the upper abscissa indicate the HALOE measurement times.

lower than the upper limit values discussed above but not inconsistent with our upper limit values.

\section{Conclusions}

The phase relationship between the perturbation of long lived tracer fields and the QBO winds will be affected by the extratropical mixing of trace gases. Using UARS CLAES $\mathrm{N}_{2} \mathrm{O} / \mathrm{CH}_{4}$ ratio, the mixing time estimate is found to be longer than 18 months in the QBO region $(20-30 \mathrm{~km})$. The depletion time of HALOE observed tropical stratospheric water vapor anomalies ascending between $20-35 \mathrm{~km}$ has about the same time scale (with perhaps more rapid depletion from $28-35 \mathrm{~km}$ ).
Using the QBO scale of $1800 \mathrm{~km}$, this suggests an eddy diffusion coefficient of $6-7 \times 10^{8} \mathrm{~cm}^{2} / \mathrm{sec}$ or lower.

The implication of these results is that the mixing of trace gases into the tropical QBO region $(20-28 \mathrm{~km})$ is quite slow and that in the QBO region the tropical pipe model of Plumb [1996] is a reasonable representation. As a result of this isolation, exhaust products deposited into the tropics or entrained below the $\mathrm{QBO}$ region would be isolated from mid latitudes as they are lofted by the mean tropical upwelling.

Acknowledgments. This research was partially supported by the EOS Interdisciplinary Science Program. 


\section{References}

Avallone. L. M. and M. Prather, Photochemical evolution of ozone in the lower tropical stratosphere, J. Geophys Res., 101,.1457-1461, 1996.

Choi, W. et al., Role of the quasi biennial oscillation in the transport of aerosols from the tropical stratospheric reservoir to mid-latitudes, $J$. Geophys Res., submitted, 1995.

Dunkerton, T. J. Nonlinear propagation of zonal winds in an atmosphere with Newtonian cooling and equatorial wavedriving, J. Atmos. Sci, 48, 236-263, 1991.

Grant, W., et al., Use of volcanic aerosols to study the tropical stratospheric reservoir, J. Geophys. Res., I0I, 3973-3988, 1996.

Harries, J. E., et al., Validation of the measurements of water vapor from the Halogen Occultation Experiment (HALOE) J. Geophys. Res., 10I, 10205-10216, 1996.

Hasebe, F, Quasi-biennial oscillations of ozone and diabatic circulation in the equatorial stratosphere, J. Aimios. Sci., 51, 729-745, 1994.

Holton, J. R., Meridional distribution of stratospheric trace constituents. $J$. Atmor. Sci., 43, 1238-1242. 1986.

Jackman, C. J, P. A. Newman, P. D. Gutherie and M. R. Schoeberl, Effect of computed horizontal diffusion coefficients on two dimensional N2O model distributions, J. Geophys. Res., 93, 5213-5219, 1988.

Minschwaner, K. et al., The bulk properties of isentropic mixing into the tropics in the lower stratosphere, J. Geophys. Res., I01,9433-9439, 1996

Minschwaner, $\mathrm{K}$. et al., Absorption of solar radiation by $\mathrm{O}_{2}$ : Implications for $\mathrm{O}_{3}$ and lifetimes of $\mathrm{N}_{2} \mathrm{O}, \mathrm{CFCl}_{3}$ and $\mathrm{CF}_{2} \mathrm{Cl}_{2}, J$. Geophys. Res. 98. 10543-10561, 1993.

Mote, P., et al.., An atmospheric tape recorder: the imprint of tropical tropopause temperatures on stratospheric water vapor, J. Geophys. Res., 101, 3989-4006, 1996.

NASA, The Atmospheric Effects of Stratospheric Aircraft,: Report of the 1992 Models and Measurements Workshop, NASA Reference Publication. 1292, Vol. 1, 1993.

NASA, Scientific Assessment of the Atmospheric Effects of Stratospheric Aircraft, NASA Reference Publication, 1381, 1995.
Ortland, D. A., et al., Measurement of stratospheric winds by the high resolution Doppler imager, J. Geophys. Res., in press, 1996.

Plumb, R. A., A "tropical pipe" model of stratospheric transport, $J$. Geophys. Res., 101, 3957-3972, 1996.

Plumb, R. A. and R. C Bell, A model of the quasi-biennial oscillation on an equatorial beta-plane, Quart. J. Roy. Meteor. Soc., 108, 335-352, 1982.

Roche, A. E., et al.. Validation of $\mathrm{CH}_{4}$ and $\mathrm{N}_{2} \mathrm{O}$ measurements by the cryogenic limb array etalon spectrometer instrument on the Upper Atmosphere Research Satellite, J. Geophys. Res., 101, 9679-9710, 1996.

Rosenfield, J. E., M. R. Schoeberl, and M. A. Geller, A computation of the stratospheric diabatic circulation using an accurate radiative transfer model, J. Atmos. Sci, 44. 859-876, 1987.

Rosenlof, K., The seasonal cycle of the residual mean meridional circulation using the downward control principle, J. Geophys. Res. 100. 5173-5191, 1995 .

Russell, J. M., et al., The halogen occultation experiment, J. Geophys. Res., 98. 10777-10798, 1993.

Trepte C. R., and M. Hitchman, Tropical stratospheric circulation deduced from satellite aerosol data, Nature, 335, 626-628, 1992.

Volk C. M. et al. Quantifying transport between the tropical and midlatitude stratosphere, Science. 272, 1763-1768, 1996.

Waugh, D. W., Seasonal variation of isentropic transport of the tropical stratosphere, J. Geophys. Res.. 101, 4007-4024, 1996.

Weisenstein, D. K, M. K. W. Ko, N-D. Sze and J. M. Rodriguez, Potential impact of $\mathrm{SO}_{2}$ emissions from stratospheric aircraft on ozone, Geophys. Res. Lett. 23, 161-164, 1996.

Corresponding author: M. R. Schoeberl. NASA Goddard Space Flight Center, Code 910, Greenbelt, MD 20771 (e-mail:

schom@zephyrgsfc.nasa.gov)

(Received: July 2, 1996, revised: September 18, 1996, accepted: October 18, 1996) 